\title{
DIREITO À EDUCAÇÃO E OBRIGATORIEDADE ESCOLAR NO BRASIL: ENTRE A PREVISÃO LEGAL E A REALIDADE ${ }^{1}$
}

\author{
Simone de Fátima Flach ${ }^{2}$ \\ Universidade Estadual de Ponta Grossa - UEPG
}

\section{RESUMO}

O texto apresenta, através de uma exposição histórica, a relação existente entre o direito à educação e a obrigatoriedade escolar na realidade brasileira, tendo como pressuposto a legislação pertinente à matéria e dados sobre a efetivação dos dispositivos legais na realidade concreta. A educação é entendida como um dos componentes da cidadania de um povo e como tal imprescindível para o seu usufruto. Como a efetivação do direito à educação pressupõe ações e instituições do poder público e, consequentemente, opções político-governamentais, conclui-se que o direito à educação, relativo à obrigatoriedade escolar, esteve e está situado em um campo frágil, pois a previsão legal e a realidade estão distanciadas, evidenciando a fragilidade da cidadania os indivíduos em idade escolar no Brasil.

Palavras-chave: direito à educação, educação obrigatória, legislação educacional.

\section{RIGHT TO EDUCATION AND OBLIGATION SCHOOL IN BRAZIL: ESTIMATED BETWEEN LEGAL AND REALITY}

\begin{abstract}
The paper presents, through an historical exhibit, the relationship between the right to education and compulsory education in the Brazilian reality, presupposing the legislation concerning this matter and data on the enforcement of legal provisions on concrete reality. Education is understood as a component of the citizenship of a people and as such essential for your enjoyment. As the realization of the right to education presupposes actions and institutions of government and therefore political-governmental options, it is concluded that the right to education on the compulsory school, was and is situated in a weak field, since the legal provision and the reality falls far, highlighting the fragility of citizenship individuals of school age in Brazil.
\end{abstract}

Keyworks: right to education, compulsory education, educational legislation.

\section{INTRODUÇÃO:}

Em uma sociedade desigual, onde a cidadania é frágil, as políticas públicas (dentre as quais situamos a educação) baseiam-se em pressupostos defendidos ou aceitos por aqueles que detêm o poder político. Tais pressupostos não se limitam apenas aos compromissos políticos, envolvem também aspectos sociais, culturais e econômicos locais, nacionais e internacionais.

Apesar de defendermos a imprescindibilidade do acesso ao saber produzido historicamente pelos seres humanos como fator necessário e componente da cidadania de 
um povo, não podemos deixar de considerar que, atualmente, o desenvolvimento social e coletivo de uma nação está vinculado à lógica que rege o capitalismo mundial. Superar a lógica capitalista que rege a vida dos indivíduos de um país supõe condições que viabilizem a sua compreensão com vistas à tomada de decisão coletiva. Uma das condições necessárias para esse processo de conscientização e conseqüente tomada de decisão sobre os rumos sociais, políticos e econômicos da sociedade é oferecida pela instituição escola, atualmente responsável em oferecer aos indivíduos o contato com o conhecimento historicamente desenvolvido pelos seres humanos e dessa forma contribuir para o contínuo desenvolvimento dos cidadãos.

$\mathrm{O}$ acesso e a permanência dos indivíduos na escola contribuem para a democratização dos conhecimentos e cria condições individuais e coletivas para o desenvolvimento da consciência sobre a realidade social em que vivem e sobre as relações existentes nos contextos dos quais são sujeitos históricos, econômicos e políticos. Ao se conscientizar de tudo isso, o indivíduo se transforma e passa a viver a sua cidadania de maneira mais efetiva. $\mathrm{Na}$ esteira desse entendimento, são esclarecedoras as palavras de Octávio Ianni:

\footnotetext{
Poucos são os que dispõem de condições para se informarem e posicionarem diante dos acontecimentos mundiais, tendo em conta suas implicações locais, regionais, nacionais e continentais. Quando se criam condições mais plenas para a elaboração da autoconsciência, no sentido de consciência para si, então a cidadania se realiza propriamente como soberania. (IANNI, 1999. p. 115).
}

Nessa perspectiva a educação e a escola se tornam essenciais para o indivíduo e para a sociedade, extrapolando fronteiras e promovendo o avanço da humanidade. No entanto, para que isso ocorra de forma efetiva há necessidade da existência de políticas públicas voltadas para o setor educacional. No contexto brasileiro a discussão sobre a existência de políticas públicas voltadas para as necessidades da população é matéria contraditória. É sobre algumas das contradições existentes nesse campo que o texto se propõe apresentar.

\section{EDUCAÇÃO E DIREITO À EDUCAÇÃO NO BRASIL: ENTRE O LEGAL E O REAL}

Embora a discussão sobre a educação, suas contribuições para o avanço de uma sociedade e a sempre necessária implementação de políticas sérias para o setor não seja recente no contexto mundial, a realidade brasileira ainda é precária em propostas e ações concretas que demonstrem compromisso com as reais necessidades dos indivíduos. Considerando a história social, política e educacional brasileira, podemos afirmar que a existência de uma política de educação voltada para o povo em sua totalidade ainda está em processo de efetivação.

Desde que o país deixou de ser Império e tornou-se uma República, as questões educacionais têm contribuído para acaloradas discussões, tanto entre especialistas quanto entre leigos.

Considerando como essencial a escolarização da totalidade da população para que tanto o direito à educação como a cidadania deixem de ser discurso e se tornem fato concreto, pode-se afirmar que essa discussão ainda é muito recente no contexto brasileiro. A República herdou do Período Imperial um contexto educacional bastante complicado, visto que a alfabetização das crianças não era preocupação do poder público. A esse 
respeito nos oferecem importante reflexão as palavras de Florestan Fernandes quando afirmou:

É certo que a República falhou em suas tarefas educacionais. Mas falhou por incapacidade criadora: por não ter produzido os modelos de educação sistemática exigidos pela sociedade de classes e pela civilização correspondente, fundada na economia capitalista, na tecnologia científica e no regime democrático. Em outras palavras, suas falhas provêm das limitações profundas, pois se omitiu diante da necessidade de converterse em Estado educador, em vez de manter-se como Estado fundador de escolas e administrador ou supervisor do sistema nacional de educação. Sempre tentou, não obstante, enfrentar e resolver os problemas educacionais tidos como "graves", fazendo-o naturalmente segundo forma de intervenção ditada pela escassez crônica de recursos materiais e humanos. Isso explica por que acabou dando preeminência às soluções educacionais vindas do passado, tão inconsistentes diante do novo estilo de vida e das opções republicanas, e por que simplificou demais a sua contribuição construtiva, orientando-se no sentido de multiplicar escolas invariavelmente obsoletas, em sua estrutura e organização, e marcadamente rígidas, em sua capacidade de atender às solicitações educacionais das comunidades humanas brasileiras. (FERNANDES, 1966. p. 4).

A República não representou transformação social ou educacional, visto que o limite existente na formulação de uma política educacional voltada para a população foi superior às possibilidades existentes com a nova organização política.

Segundo a abordagem de Otaíza de Oliveira Romanelli (1986), no período inicial da República o poder exercido pelas oligarquias rurais projetava no sistema escolar a mentalidade colonial; a burguesia industrial em ascensão tinha como referência a classe latifundiária e as classes emergentes não tinham afinidade com as camadas mais pobres da população e, ainda, viam a educação como possibilidade de preservação da estrutura aristocrática existente até então. Esse quadro fortaleceu um sistema dual de ensino através de oportunidades educacionais diferenciadas, conforme a classe em que o indivíduo se encontrava: "de um lado, o ensino primário, vinculado às escolas profissionais, para os pobres, e de outro, para os ricos, o ensino secundário articulado ao ensino superior, para o qual preparava o ingresso." (ROMANELLI, 1986, p. 67).

A ausência de uma política educacional, enquanto proposta governamental, que pudesse oferecer à população acesso à escola primária e possibilidade de avanço no sistema educacional pode ser apontada como um limite político que não visualizava a escola como componente na construção de uma nação independente. As reivindicações pela elaboração de uma política educacional, pautada nas necessidades da população, emergem de movimentos não necessariamente ligados ao poder instituído. Uma das propostas mais importantes que reivindicava a elaboração de uma política educacional consistente encontra-se no documento elaborado por Fernando de Azevedo na década de 1930, endereçado ao Povo e ao Governo Brasileiro propondo a Reconstrução Educacional no Brasil. Esse documento ficou conhecido como "Manifesto dos Pioneiros da Educação Nova" e reafirmava a importância da educação tanto para o desenvolvimento do país, quanto para o desenvolvimento da cidadania para a população brasileira.

Embora naquele momento histórico a discussão se centrasse na oferta da escola para todos, visto que a educação existente poderia ser considerada como privilégio para determinada camada da sociedade, podemos retirar do referido documento a sempre 
presente preocupação em demonstrar o quão relevante se torna o processo educacional para o desenvolvimento do povo. Para a importante tarefa de fomentar uma verdadeira revolução social, os signatários do manifesto enalteciam sobremaneira a ação da escola.

Mais do que um problema localizado no setor educacional, o Manifesto dos Pioneiros situa o problema educacional como eminentemente social, conforme analisou Otaíza de Oliveira Romanelli, indicando a educação como possibilidade para alavancar o desenvolvimento econômico brasileiro e conseqüentemente possibilitar também o desenvolvimento da sociedade.

Desprendendo-se dos interesses de classes, a que ela tem servido, a educação perde o "sentido aristológico", para usar a expressão de Ernesto Nelson, deixa de constituir um privilégio determinado pela condição econômica e social do indivíduo, para assumir um "caráter biológico", com que ela organiza a coletividade em geral, reconhecendo a todo o indivíduo o direito a ser educado até onde o permitam as suas aptidões naturais, independente de razões de ordem econômica e social. A educação nova, alargada a sua finalidade para além dos limites das classes, assume, com uma feição mais humana, a verdadeira função social, preparando-se para formar "a hierarquia democrática" pela "hierarquia das capacidades", recrutadas em todos os grupos sociais, a que se abrem as mesmas oportunidades de educação. Ela tem, por objeto, organizar e desenvolver os meios de ação durável com o fim de "dirigir o desenvolvimento natural e integral do ser humano em cada uma das etapas de seu crescimento", de acordo com certa concepção de mundo. (AZEVEDO et al. 2010, p. 40)

Ao reconhecer a educação como direito de todos, enaltecendo a sua função eminentemente social e pública, o Manifesto dos Pioneiros dá um salto qualitativo na compreensão da temática educacional como essencial para o desenvolvimento da cidadania na nação em formação. Nesse sentido, é importante ressaltar o papel desempenhado no contexto do Manifesto, que trouxe em seu bojo as importantes reivindicações de uma educação pública, obrigatória, gratuita, leiga e igual para ambos os sexos. Essas reivindicações tomadas como princípios fundamentais para a educação brasileira demonstram o quão importante é sua efetivação para que a conquista da cidadania seja real, considerando o contexto em que se insere a temática, extinguindo-se os privilégios de classe, até então existentes e superando a organização escolar que privilegiava alguns em detrimento de uma grande maioria. Ao ser ministrada de forma geral, comum e igual para todos os brasileiros, a educação fortaleceria a igualdade necessária entre as pessoas que compõem o povo brasileiro.

Assentado o princípio do direito biológico de cada indivíduo à sua educação integral, cabe evidentemente ao Estado a organização dos meios de o tornar efetivo, por um plano geral de educação, de estrutura orgânica, que torne a escola acessível, em todos os seus graus, aos cidadãos a quem a estrutura social do país mantém em condições de inferioridade econômica para obter o máximo de desenvolvimento de acordo com suas aptidões vitais. Chega-se, por esta forma, ao princípio da escola para todos, "escola comum ou única", que tomando a rigor, só não ficará na contingência de sofrer quaisquer restrições, em países em que as reformas pedagógicas estão intimamente ligadas com a 
reconstrução fundamental das relações sociais. (AZEVEDO et al. 2010, p. 44)

Em uma sociedade assentada na desigualdade, a proposição de uma educação conforme as "aptidões" ou "direito biológico" não nos parece realmente voltada para o direito à educação. Em uma sociedade de classes, a desigualdade é fundamental para a proposição de alternativas político-educacionais, pois a partir dela é que as propostas necessitam emergir, sob pena de ignorá-las e o discurso de igualdade não sair do plano das idéias, visto que a desigualdade existente ser determinante para o acesso ao saber sistematizado. As necessidades materiais dos indivíduos nessa sociedade são mais prementes do que as necessidades intelectuais. Essa questão não pode ser desconsiderada quando se tem a superação da desigualdade, seja social, econômica ou educacional, como meta.

Ao analisar o "Manifesto", Dermeval Saviani chama a atenção para a natureza contraditória do documento ao expressar concepções diferentes e até divergentes ou incompatíveis, além de expressar, também, os interesses políticos de seus signatários.

Em termos políticos o "Manifesto" expressa a posição de uma corrente de educadores que busca se firmar pela coesão interna e pela conquista da hegemonia educacional diante do conjunto da sociedade capacitando-se, conseqüentemente, ao exercício dos cargos de direção da educação pública tanto no âmbito do governo central como dos Estados federados. (SAVIANI, 2007, p. 253).

No entanto, apesar das contradições e interesses evidenciados em seu texto, o "Manifesto" tornou-se um importante documento por trazer à centralidade da discussão os problemas educacionais brasileiros, impulsionando o posicionamento de educadores e pessoas ligadas ao governo sobre questão tão contundente na realidade brasileira. Também é preciso considerar que o "Manifesto dos Pioneiros" foi um documento gestado no seio das discussões da intelectualidade liberal engajada politicamente, membros da classe dominante, ele não possuiu efetividade prática por si só, mas, influenciou sobremaneira o pensamento na área educacional e deixou registrada a defesa do direito das crianças e jovens de 7 a 15 anos a uma educação integral. Inclusive alguns dos princípios defendidos naquele documento foram discutidos e inseridos no texto da Constituição de 1934.

Embora não se possa negar que o Manifesto dos Pioneiros da Educação Nova tenha se constituído em um documento político influenciando o pensamento educacional brasileiro, alguns autores apontam para os limites do documento. Dentre os limites apontados, podemos evidenciar a desconsideração pela divisão da sociedade em classes dominantes e dominados (RIBEIRO, 1991, p. 112), além da "colagem de princípios elitistas e igualitaristas" (CUNHA, 1994, SAVIANI, 2007), o que resulta em um documento deslocado da realidade sócio-educacional brasileira. No entanto, consideramos que as influências do pensamento dos Pioneiros na educação brasileira, principalmente em relação ao registro histórico da necessidade de assegurar escola para as crianças e jovens, podem ser considerados como relevantes.

Sob os limites ou não do referido documento, o texto constitucional de 1934, embora efêmero, representou a legitimação de alguns avanços educacionais para a sociedade brasileira, muitos deles retirados do texto constitucional de 1937 e depois retomados novamente em 1946. 
Ao estabelecer em seu art. 149 que "a educação é direito de todos e deve ser ministrada pela família e pelos poderes públicos", a Constituição de 1934 ofereceu importante mostra sobre a necessidade de direcionar ações para o contexto educacional brasileiro. No entanto, a mesma Carta Magna, ao estabelecer normas para o Plano Nacional de Educação e competências da União faz duas indicações que interferem substancialmente no acesso à educação enquanto direito de cidadania.

A alínea "a" do Parágrafo Único do Art. 150 previu que o ensino primário seria gratuito e de frequiência obrigatória, porém, sem estabelecer a oferta obrigatória, o que não obrigou o poder público a envidar esforços para que a população tivesse acesso real à escola elementar. Isso fica mais evidente na alínea "e" do mesmo Parágrafo Único que previu a limitação da matrícula à capacidade didática do estabelecimento e seleção por meio de provas de inteligência e aproveitamento.

Em termos práticos, a previsão de ensino gratuito e obrigatório teve pouco avanço real, visto que, conforme apontado por Maria Luisa Santos Ribeiro, o período de 1932 1936 teve uma "certa ampliação na organização escolar brasileira, mas insuficiente para sua transformação" (RIBEIRO, 1991, p. 105), ou seja, houve a ampliação da rede escolar, das matrículas em geral e do número de professores, mas, essa ampliação não foi acompanhada de melhora qualitativa significativa. Ainda, segundo a mesma autora, os alunos continuaram sendo reprovados, $81 \%$ dos estabelecimentos funcionavam como escolas isoladas, houve um afunilamento entre os alunos concluintes do ensino elementar e do ensino médio e superior, demonstrando a seletividade existente na escola brasileira.

Embora a Constituição de 1934 tenha expressado em seu texto questões importantes para a educação, esse documento teve uma vida muito efêmera, devido ao processo social e político que o sucedeu. O golpe de Estado que instalou o Estado Novo trouxe consigo a outorga de uma nova Constituição - a de 1937 - a qual reprimiu muitas das conquistas educacionais expressas no texto constitucional anterior.

Em relação à obrigatoriedade e gratuidade da educação primária, o texto constitucional de 1937 é mais enfático, ao declarar em seu art. 130 que "O ensino primário é obrigatório e gratuito", apontando para a responsabilidade do poder público na garantia desse nível de ensino. No entanto, o mesmo artigo retira a responsabilidade do Estado com a gratuidade da oferta desse nível de ensino, quando estabelece que "a gratuidade, porém, não exclui o dever de solidariedade dos menos para com os mais necessitados; assim, por ocasião da matrícula, será exigida aos que não alegarem, ou notoriamente não puderem alegar escassez de recursos, uma contribuição módica e mensal para a caixa escolar." (COSTA, 2002, p. 42).

Da mesma forma que a limitação de matrículas previstas na Constituição de 1934, a exigência de contribuição para a caixa escolar prevista na Constituição de 1937, além de demonstrar uma concepção limitada, senão estreita sobre a obrigatoriedade e gratuidade do ensino, pode ter contribuído de forma sui generis para que a procura pela escola e a permanência nela se mostrassem de difícil efetividade. Quanto às questões práticas de tal previsão, visto a inexistência de dados, podemos supor que a gratuidade parcial prevista no texto constitucional demonstra uma concepção discriminatória em relação às classes sociais que compõem a sociedade brasileira, fortalecendo a separação entre as mesmas. Essa previsão e a manutenção de uma organização educacional com baixo desempenho, em que, segundo análise de Maria Luisa Santos Ribeiro (1991), no período de 1935 1955, em torno de $15 \%$ dos matriculados não freqüentavam a escola regularmente e metade dos matriculados ficavam retidos em razão da organização interna do processo educativo, podem ser indicadores de uma educação que privilegiava poucos em detrimento 
da maioria da população brasileira. Apesar da expansão de matrículas, nesse período, a escola elementar (primária) brasileira permanece com baixo desempenho qualitativo.

Até 1945, o ensino primário não foi o foco de atenção do governo central, estando sua organização vinculada aos governos estaduais, o que criava uma distorção em sua oferta, devido à falta de diretrizes gerais. Cada estado organizava esse nível de ensino, conforme os interesses localizados no espaço político de abrangência estadual e as reformas implementadas estavam vinculadas aos interesses expressos em tais políticas, o que contribuía para uma desigualdade regional em relação à educação oferecida à população. (ROMANELLI, 1986, p. 160).

O Decreto-lei no 8529, de 02 de janeiro de 1946, também chamado de Lei Orgânica do Ensino Primário, traçou diretrizes para esse nível de ensino para todo o país, desdobrando-o em duas categorias de ensino: o ensino primário fundamental, destinado às crianças de sete a doze anos, sendo desdobrado ainda em ensino primário fundamental, com duração de quatro anos e o ensino primário complementar, com duração de um ano, acrescentado ao fundamental. O Decreto-lei previa, ainda, o ensino primário supletivo, destinado aos adolescentes e adultos, com duração de dois anos.

Segundo Dermeval Saviani, a tendência para a organização da educação brasileira baseou-se em reformas parciais, em que as urgências educacionais eram regulamentadas conforme os interesses daqueles que assumiam o controle político do país, sem um planejamento político-educacional amplo e que abrangesse o todo da educação brasileira, conforme preconizado pelo Manifesto dos Pioneiros em 1932.

A Reforma do Ensino Primário, instituída pelo Decreto-lei 8529/46, além de possibilitar uma organização mais unitária do ensino primário no país, possibilitou um avanço na luta contra o analfabetismo, visto que a organização do ensino primário supletivo contribuiu para a "diminuição da taxa de analfabetismo, no final da década de 40 e toda a década de 50" (ROMANELLI, 1986, p.161).

$\mathrm{Na}$ realidade nacional brasileira os princípios de gratuidade e obrigatoriedade do ensino se tornam extremamente importantes para a garantia de acesso e freqüência à escola. Esses princípios foram contemplados na Reforma do Ensino Primário (Decreto-lei $\mathrm{n}^{\circ} 8529$ de 02 de janeiro de 1946). Quanto à gratuidade, o Decreto lei $\mathrm{n}^{\circ} 8529 / 46$, em seu art. 39 previa o ensino primário como gratuito, embora possibilitasse a organização de caixas escolares com a contribuição das famílias dos alunos. Quanto à obrigatoriedade, o art. 41 declarava que "o ensino primário elementar é obrigatório para todas as crianças nas idades de sete a doze anos, tanto no que se refere à matrícula como no que diz respeito à freqüência regular às aulas e exercícios escolares".

A previsão legal não é garantia de transformação na realidade, a qual necessita de um conjunto de fatores que contribuem para essa transformação. A eficácia legal só é possível quando há um conjunto de ações extra e intra-escolares - ações governamentais, sociais e de organização interna do processo educativo - em prol de objetivos que tenham o compromisso de interferir no contexto existente, ou seja, a legislação só será eficaz se as pessoas envolvidas no processo estiverem realmente comprometidas com a sua aplicação. Uma lei, por mais avançada que seja, pode tornar-se letra morta no campo de sua execução, assim como uma lei retrógrada pode contribuir para avanços no contexto, dependendo dos homens que a aplicam. Em um país recém saído de um regime escravocrata, onde a sociedade foi formada com base em privilégios e a organização produtiva ainda estava em estágio inicial de industrialização, a importância da educação formal ainda não era valorizada pela população e o poder público muitas vezes pautava suas ações pela inércia. Também não havia mecanismos formais de cobrança do 
cumprimento dos dispositivos legais de gratuidade e obrigatoriedade, tanto pela população quanto pelo poder público.

A necessária previsão de um planejamento político-educacional para todo o país somente foi manifestada na promulgação da Constituição Federal de 1946 através da previsão de que "Compete à União legislar sobre as diretrizes e bases da educação nacional" (art. $5^{\circ}$, inciso XV, alínea 'd'). No entanto, o cumprimento desse dispositivo constitucional somente foi efetivado com a Lei 4024, de 20 de dezembro de 1961, a Lei de Diretrizes e Bases da Educação Nacional.

É importante ressaltar que a Constituição de 1946 declara a educação como direito de todos (art. 166) e o ensino primário como obrigatório e gratuito (art. 168, I e II). Essa previsão constitucional pode ser considerada como uma garantia da educação como um dos componentes necessários para a cidadania do povo brasileiro, uma vez que possibilita que todos freqüentem a escola, sem qualquer restrição legal. Eis o texto constitucional:

Art. 168. A legislação do ensino adotará os seguintes princípios:

I - o ensino primário é obrigatório e só será dado na língua nacional;

II - o ensino primário oficial é gratuito para todos; o ensino oficial ulterior ao primário sê-lo-á para quantos provarem falta ou insuficiência de recursos. (COSTA, 2002, p. 50)

Para que a educação se efetive como um dos elementos da cidadania precisa de implementação adequada, ou seja, além da revisão legal, necessita de vontade política e recursos adequados para a sua garantia, ou seja, necessita de instituições que estejam organizadas e preparadas para esse trabalho educativo. A Constituição de 1946 previa a aplicação percentual de recursos públicos no setor educacional, o que demonstra uma preocupação na oferta de condições mínimas para que o direito à educação fosse minimamente assegurado. O art. 169 previa a aplicação da União, Estados e Distrito Federal de nunca menos de dez por cento e dos Municípios a aplicação de nunca menos de vinte por cento de suas rendas na manutenção e desenvolvimento do ensino.

Considerando a educação como um direito social, podemos inscrever a Constituição de 1946 e a previsão de recursos para aplicação no setor educacional como um compromisso público de garantia para a efetividade de tal direito, principalmente quando os princípios de obrigatoriedade e gratuidade se mostram tão explícitos no texto constitucional, mesmo que tal compromisso não tenha efetividade na prática da política educacional, conforme a história vem demonstrando, visto que o Brasil ainda persegue, nos dias atuais, essa questão.

Em Conferência proferida em 1960, Paulo Freire realiza um diagnóstico da educação primária no Brasil, apontando características excludentes da educação brasileira, demonstrando a necessidade urgente de modificação da realidade educacional em busca de assegurar para a maioria da população o direito de aprender na escola. A aprendizagem defendida por Freire mostra-se intimamente ligada à concepção que defendemos,segundo a qual, todos, indistintamente devem ter acesso, permanecer e aprender na escola. Mas, para que isso aconteça é necessária, assim como apontado pelo autor, uma reorganização interna e externa da escola de modo a tornar a educação mais próxima e viva aos pequenos brasileiros. $\mathrm{O}$ acesso à escola era insuficiente e, ainda, para aqueles que alcançavam tal intento, a organização interna da escola sentenciava que em torno de $62 \%$ dos matriculados na $1^{\text {a }}$ série eram reprovados ou evadiam-se do sistema escolar. Essa realidade demonstra que o direito à educação, infelizmente não era assegurado ideal e formalmente. Paulo Freire reafirma que a educação brasileira precisava superar o "ciclo vicioso" no qual o 
subdesenvolvimento é justificado pela falta de educação e saúde, e, a falta destas devido ao subdesenvolvimento.

Indo além do pensamento de Freire, a necessidade urgente de oferecer educação para todas as crianças e jovens encontra limites na lógica social brasileira, passada e presente, na qual o direito à educação é diferenciado conforme a origem de classe do alunado.

É no contexto apontado por Paulo Freire, e depois de uma longa tramitação, que, em 20 de dezembro de 1961, é sancionada a Lei de Diretrizes e Bases da Educação Nacional (Lei $\mathrm{n}^{\circ}$ 4024/61), a qual pode ser considerada como um grande passo para a unificação do ensino no país. Todavia, essa sancionou as distorções existentes, não modificando substancialmente o sistema educacional.

A Lei 4024/61 previa a obrigatoriedade do ensino primário, apontando para o avanço em relação à declaração do direito à educação ao tal nível de ensino como obrigatório.

Art. 27. O ensino primário é obrigatório a partir dos sete anos e só será ministrado na língua nacional. Para os que o iniciarem depois dessa idade poderão ser formadas classes especiais ou cursos supletivos correspondentes ao seu nível de desenvolvimento. (BRASIL, 1961)

Mas, é preciso considerar que a obrigatoriedade escolar é condição essencial para o poder público criar condições institucionais para a garantia da educação, principalmente em um país de longa tradição negativa em relação à oferta e às condições para que o direito à educação seja assegurado. No entanto, é preciso que a frequiência à escola não se restrinja apenas à alfabetização, mas ultrapasse essa etapa e, ainda, atinja a totalidade da população.

Nesse sentido, a escolarização no nível primário no contexto analisado encontra-se ligado aos interesses da burguesia brasileira da época, não representando uma real ampliação do direito à educação. A incapacidade da burguesia em assegurar educação de forma universal foi apresentada por Mario Alighero Manacorda quando analisou os avanços educacionais defendidos pelas Revoluções Burguesas frente ao entendimento do marxismo.

O marxismo não rejeita, mas assume todas as conquistas ideais e práticas da burguesia no campo da instrução já mencionadas: universalidade, laicidade, estatalidade, gratuidade, renovação cultural, assunção da temática do trabalho, como também a compreensão dos aspectos literário, intelectual, moral, físico, industrial e cívico. O que o marxismo acrescenta de próprio é, além de uma dura crítica à burguesia pela incapacidade de realizar seus programas, uma assunção mais radical e conseqüente dessas premissas e uma concepção mais orgânica da união instrução-trabalho na perspectiva oweniana de uma formação total de todos os homens.( MANACORDA, 2006. )

No mesmo sentido, o direito à educação, conforme previsto no art. $3^{\circ}$ da Lei 4024/61 representa a explicitação de uma bandeira burguesa, a qual pode ser considerada um avanço (contraditório, mas avanço) visto que buscou assegurar educação para todos. No entanto, a obrigação do poder público em assegurar educação primária para a totalidade da população foi substancialmente amenizada com o dispositivo que previa situações de exceção em relação à matrícula, tornando isento daquela obrigação o responsável que não efetivasse a matrícula de criança em idade escolar. Eis as exceções previstas: comprovado estado de pobreza do pai ou responsável, insuficiência de escolas, matrícula encerrada; 
doença ou anomalia grave da criança (Parágrafo único do art. 30). Tais previsões induzem o entendimento de desobrigação do poder público para com a obrigatoriedade em assegurar escolarização para as crianças em idade escolar.

Se atentarmos para o fato de que, na época, a maioria da população ativa da nação ganhava um salário que não era suficiente para a simples sobrevivência; que a parte não ativa da população adulta, assim o era por causa do desemprego e constituía um contingente superior à população ativa; que a economia de subsistência geradora de um estado de pobreza crônico ocupava a maior parte do território nacional e, finalmente, que, segundo dados do censo escolar de 1964 (portanto 3 anos depois da vigência da lei), nesse ano, 33,7\% das pessoas de 7 a 14 anos não freqüentavam escolas, em sua maioria por falta destas, a conclusão a que se pode chegar, quanto ao art. 30 da Lei de Diretrizes e Bases, é que os poderes públicos simplesmente resolveram oficializar uma situação anormal existente, sem se darem o cuidado de corrigi-la ou pelo menos atenuá-la. (ROMANELLI, 1986, p. 181)

A situação apontada pela autora acima citada não reduz a importância da Lei 4024/61 quanto à obrigatoriedade das crianças em idade escolar freqüentarem a escola, pois, ainda que precário o atendimento, o ensino primário foi previsto com certo grau de importância, visto que tanto o poder público quanto pais ou responsáveis seriam responsáveis pelas referidas matrículas. Mais uma vez faltava a previsão de mecanismos adequados para que tal previsão rompesse com a mera prescrição formal e fosse revestida de ações efetivas, as quais poderiam colaborar significativamente para que a população avançasse na efetivação do direito à educação. O poder público mostrou-se incapaz de efetivar os mecanismos adequados para cumprir o dispositivo legal, seja ampliando o número de vagas e escolas, a contratação de professores formados para tal tarefa e, ainda, instituir mecanismos que fiscalizassem e garantissem que os pais ou responsáveis matriculassem as crianças, além de destinar recursos adequados para tal. Dessa forma, a previsão ficou no nível da formalidade e não no da realidade concreta dos brasileiros.

No contexto da implementação dos dispositivos da Lei 4024/61, e atendendo dispositivo constitucional, em 1962 o Conselho Federal de Educação aprovou o Plano Nacional de Educação que teve, dentre inúmeras metas, a de garantir a matrícula até a quarta série de $100 \%$ da população escolar de 7 a 11 anos. Essa meta, apesar de não alcançada, é importante por demonstrar a necessidade de assegurar que as crianças em idade escolar tivessem, pelo menos, acesso à escolarização formal. Infelizmente, passado, hoje, quase meio século, o Brasil ainda não conseguiu atingir a meta estabelecida naquele Plano Nacional de Educação.

A extensão da escolaridade parece ter sido uma meta bastante importante, mas a produtividade do sistema deixou a desejar, pois os altos índices de reprovação faziam com que os alunos se evadissem ou permanecessem no sistema sem avanços significativos.

Durante o período de ditadura militar e sob a égide da Constituição de 1967, reformulada pela Emenda Constitucional $\mathrm{n}^{\mathrm{o}} 1$ de 17 de outubro de 1969, o direito à educação no Brasil não sofreu mudanças substanciais, o que demonstra a desconsideração do regime pela instrução e formação intelectual da população, principalmente em relação aos anos iniciais de escolarização. Sob a influência de acordos internacionais, em 1971 foi aprovada a Lei 5692, que propunha uma reforma no ensino em relação ao antigo ensino primário e médio (ginasial e colegial), instaurando o ensino de $1^{\circ}$ e $2^{\circ}$ graus. Para $o$ objetivo deste texto convém ressaltar o disposto logo no início da referida lei: 
Art. $1^{\circ}$. O ensino de $1^{\circ}$ e $2^{\circ}$ graus tem por objetivo geral proporcionar ao educando a formação necessária ao desenvolvimento de suas potencialidades como elemento de auto-realização, qualificação para o trabalho e prepara para o exercício consciente da cidadania. (BRASIL, 1972)

Para cumprir esse objetivo foi realizada uma reestruturação do ensino, ocorrendo a ampliação da obrigatoriedade escolar de 4 para 8 anos, através da fusão dos cursos primário e ginásio. Essa organização visava extinguir a seletividade existente pelo exame de admissão ao ginásio e, ainda, instituiu a obrigatoriedade escolar para os alunos de 7 a 14 anos. Em relação à educação enquanto direito da população, a iniciativa pode ser considerada como um avanço. Mas, mais uma vez, porém, a obrigatoriedade prevista torna-se letra morta, pois não existiam recursos materiais e humanos para atender a demanda existente, além de a própria lei estabelecer a possibilidade de antecipação da iniciação para o trabalho quando a obrigatoriedade não fosse alcançada.

Ao analisar as lutas populares pelo direito à Educação na Década de 70 no município de São Paulo, Marília Pontes Spósito ressalta que as demandas educacionais naquele período estiveram sob o controle do Estado, através da "supressão da democracia política e das orientações centralizadoras do regime autoritário" (SPÓSITO,1993, p. 72) que contribuíram para o gerenciamento e articulação das formas de participação popular consentidas. Nessa perspectiva muitos representantes dos movimentos populares foram transformados em "funcionários administrativos" enfraquecendo a força coletiva em prol da educação popular.

As professoras Eneida Shiroma, Olinda Evangelista e Maria Célia Marcondes Moraes, da Universidade Federal de Santa Catarina, ao realizarem um retrospecto da política educacional brasileira a partir do materialismo histórico-dialético apresentam importantes reflexões a respeito dos impactos da legislação desse período no campo educacional.

A lei privilegiou um enfoque quantitativo e não considerou aspectos elementares para afiançar a qualidade do ensino, tais como a necessidade de rever a organização da escola e as próprias condições de efetivação real do ensino básico. $\mathrm{Na}$ verdade, o regime militar diminuiu drasticamente os recursos para a educação, que alcançaram os mais baixos índices de aplicação da história recente do país, menos de $3 \%$ do orçamento da União. O salário-educação (Lei 4420/64), originariamente concebido com o objetivo de incrementar o ensino oficial de $1^{\circ}$ grau, cumpriria o papel de principal fonte de recursos para fazer frente às necessidades do ensino fundamental. Adicionalmente, garantia apoios políticos mais fortes e seguros ao regime. A União, ao repassar recursos do salário-educação aos estados da Federação para a construção de escolas, atendia a interesses de políticos e empreiteiros locais, criando, dessa forma, uma rede de favores e dependências. Por outro lado, as verbas do salário-educação, gradativamente, foram aplicadas para subsidiar o ensino privado. No momento, então, em que a escola básica com oito anos de obrigatoriedade exigia uma intervenção clara em seus desdobramentos, fortes investimentos para sua implementação em todo território nacional, ampla discussão com educadores e educadoras de todo o país, o governo limitou-se a ampliar o clientelismo e a formular projetos de gabinete. (SHIROMA, EVANGELISTA, MORAES, 2000, p. 39) 
É importante ressaltar que a grande maioria dos iniciantes do $1^{\circ}$ grau - em torno de $80 \%$ - não conseguiam sobreviver ao sistema e iniciar o $2^{\circ}$ grau, o que demonstra uma organização escolar que não conseguia atingir o objetivo de assegurar o direito à educação à população. Mais uma vez a previsão legal não garantiu o direito de estar e aprender na escola. A organização escolar seriada, a cultura de privilégio aos melhores contribuiu para que o acesso à escola fosse mero detalhe na garantia do direito à educação. Estar na escola não significa, necessariamente, estar aprendendo na escola. Os limites internos da organização escolar e as condições externas impediam que os alunos avançassem e usufruíssem a oportunidade de acesso à escola.

Em meados da década de 1980, o quadro educacional brasileiro era dramático: $50 \%$ das crianças repetiam ou eram excluídas ao longo da $1^{\mathrm{a}}$ série; $30 \%$ da população eram analfabetos, $23 \%$ dos professores eram leigos e $30 \%$ das crianças estavam fora da escola. Além disso, 8 milhões de crianças no $1^{\circ}$ grau tinham mais de 14 anos, $60 \%$ de suas matrículas concentravam-se nas três primeiras séries que reuniam $73 \%$ das reprovações. Ademais, é importante lembrar que $60 \%$ da população brasileira viviam abaixo da linha da pobreza. Tais dados forneciam as condições para a exigência de redirecionamento na legislação educacional vigente.( (SHIROMA, EVANGELISTA, MORAES, 2000, p. 44).

Essa realidade educacional não era de todo indiferente à população, que no início dos anos 80 dava mostras da emergência em ampliar os direitos à educação, através da preocupação não apenas ao acesso ao ensino de $1^{\circ}$ grau, mas à sua continuidade e o direito das pessoas excluídas do processo educacional no período anterior.

No período de transição entre o regime militar e a abertura democrática, em meados dos anos 80, quando era visível o desgaste político da ditadura e o enfraquecimento de sua legitimidade, ocorreu, em 1982, eleição para governadores, quando a oposição mostrou-se fortalecida pela esperança de mudança. No entanto, alguns pesquisadores apontam que essa possibilidade de ruptura política foi substituída por um período de "transição" (BENVIDES, 1986; OLIVEIRA, 1987).

Antigos militantes de partidos clandestinos de esquerda, profissionais liberais ou técnicos que de certa forma assessoravam o movimento popular, diante da aliança eleitoral ou do apoio ao PMDB, passa a ocupar cargos na administração pública; lideranças populares gestadas nas lutas dos anos 70 transformam-se em funcionários públicos ou assessores de governo e órgãos intermediários da administração. (SPÓSITO, 1993, P. 109).

A realidade retratada em de São Paulo por Marília Pontes Spósito não foi diferente da ocorrida em outras regiões do país e é nesse contexto contraditório que aos poucos se constituiu uma nova agenda político-educacional, emergindo a necessidade de elaboração de uma nova Constituição Federal, voltada para a realidade de abertura política então em marcha. Assim, em 1988, sob a influência de interesses contraditórios, o Brasil teve uma Nova Constituição, elaborada sob os limites de uma organização de Estado Democrático de Direito, ainda não consolidado.

Uma Constituição não se elabora ao simples prazer dos legisladores, mas representa as reivindicações, as aspirações dos diversos segmentos da sociedade. Ela representa o 
resultado das correlações de forças, muitas vezes antagônicas, que refletem a vontade de uma nação. Isso ficou evidenciado, também, no caso brasileiro.

A Constituição de 1988 tentou dar conta das profundas mudanças ocorridas em nosso país na economia, nas relações de poder e nas relações sociais globais, nos últimos 20 anos, introduzindo temas, redefinindo papéis, incorporando às instituições sociais segmentos historicamente marginalizados, sem, no entanto, alterar substantivamente as relações sociais vigentes. (NEVES, 1999, p. 99).

Isso se justifica devido ao empenho do governo da época em direcionar suas ações baseadas num discurso de "tudo pelo social", além de ter o compromisso em romper com as amarras do militarismo ainda presente. A Constituição Federal de 1988 significou o resultado da correlação de forças entre os defensores de reabertura política, os resquícios do autoritarismo e burocratismo militar e os interesses privados no novo contexto políticoeconômico.

Em seu preâmbulo, a Constituição de 1988, anuncia a instituição de um Estado Democrático, destinado a assegurar, dentre outros preceitos, o exercício dos direitos sociais e individuais como valores supremos de uma sociedade.

O Estado Democrático de Direitos pressupunha a ampliação dos direitos sociais. A Constituição da transição, além de delimitar, modernizando, o arcabouço institucional das relações econômicas, teve seu ponto de inflexão na delimitação dos marcos institucionais de maior socialização do poder. (NEVES, 1999, p. 100).

O Estado Democrático de Direito é previsto já no parágrafo único do art. $1^{\circ}$ que diz: "Todo o poder emana do povo, que exerce por meio de representantes eleitos ou diretamente, nos termos desta Constituição". Ao declarar que "todo poder emana do povo", a Constituição assegura de forma ampla a soberania popular.

É dessa potência que se pode entender por que a legislação ganha sentido, legitimidade e prestígio. Contrariamente à lei da força, a força da lei é a ordem jurídica nascida da vontade popular que vai se impondo como o modo normal de funcionamento da sociedade, como lugar de igualdade de todos e como produto da própria cidadania. Será, pois, no reconhecimento da cidadania como capacidade de alargar o horizonte de participação de todos nos destinos nacionais que a legislação volta à cena. (CURY, 2002. p.17).

O reconhecimento da cidadania conduz à compreensão de que é " um ato pelo qual se dá a todos o conhecimento da legislação em termos de direitos, deveres, obrigações e proibições, além do funcionamento organizacional de uma sociedade”. ( CURY, 2002. p.17). Sendo o ordenamento jurídico primeiro, a partir do qual se fundamentam todas as demais leis e normatizações, a Constituição assume papel de destaque no ordenamento legal no País. Nesse sentido, seria necessário que todos conhecessem a legislação organizadora da vida individual e coletiva, mas num país profundamente excludente, como é o Brasil, essa exigência se torna irreal, já que a grande maioria da população brasileira não tem acesso aos bens culturais, e muito menos à compreensão sobre a importância do conhecimento do ordenamento jurídico. Somente aos mais instruídos e pertencentes a uma classe social elevada é natural o direito de conhecer os preceitos legais. Isso é considerado 
"normal" numa sociedade como a brasileira, pois os mais pobres e menos letrados continuam excluídos das discussões sobre a organização do País. E há, ainda, muitos analfabetos ${ }^{3}$.

Para efeito deste estudo, mostra-se essencial que o capítulo III da Constituição Federal, na seção intitulada "Da Educação", seja aqui abordado, no intuito de tornar mais clara a compreensão de direito à educação assegurado na Carta Magna. Antes mesmo do capítulo que trata especificamente da Educação, a Constituição assim assinala em seu artigo 60: "São direitos sociais a educação, a saúde, o trabalho, o lazer, a segurança, a previdência social, a proteção à maternidade e à infância, a assistência aos desamparados, na forma desta Constituição.".

A educação é, assim, "um direito social fundante da cidadania e o primeiro na ordem das citações" (CURY, 2002). Isso equivale dizer que sem educação não pode haver cidadania. Também o pleno exercício da democracia encontrar-se-á entravado se esse direito social não for amplamente assegurado à população.

Carlos Roberto Jamil Cury aponta, ainda, outros direitos assegurados constitucionalmente, mas que dependem de que o direito à educação seja efetivado.

\begin{abstract}
É importante se saber, por exemplo, que o Título II, Capítulo I, art. $5^{\circ}$ da nossa Constituição garante uma lista infinda de direitos civis dentre os quais muitos têm a ver com educação. Cito alguns: a igualdade jurídica entre homem e mulher, a liberdade de consciência e de expressão, a liberdade de associação, a condenação a todo tipo de maus-tratos e a condenação ao racismo como crime inafiançável. (CURY, 2002, p. 19).
\end{abstract}

Sendo assim, a educação colocada como direito de todos e dever do Estado e da família é entendida como primordial para o desenvolvimento do ser humano, para que este exerça plenamente a cidadania e, de quebra, obtenha qualificação para o trabalho.O status dado à educação é tão importante que o ensino gratuito e obrigatório (ensino fundamental) tornou-se direito público subjetivo nos termos do art. 208.

Após a declaração, no texto constitucional, do direito à educação à totalidade da população, convém analisar sob quais princípios a educação e o ensino estão assentados. $\mathrm{O}$ artigo 206 elenca alguns princípios sob os quais o ensino deve ser ministrado e dentre os quais torna-se necessário destacar os seguintes, por estarem diretamente vinculados à temática em questão neste texto:

Art. 206. O ensino será ministrado com base nos seguintes princípios:

I - igualdade de condições para o acesso e permanência na escola:

(...)

IV - gratuidade do ensino público em estabelecimentos oficiais;

O cumprimento destes princípios, ao que parece, está ligado à garantia do direito à educação através da previsão de igualdade de condições e não igualdade de oportunidades para o acesso e permanência na escola, evidenciando-se a preocupação do legislador em assegurar educação para todos. Todavia, para atender o inciso I, torna-se necessário uma nova reorganização social comprometida com a superação da exclusão sob a qual se edifica a sociedade brasileira, o que torna esse dispositivo com poucas possibilidades de se efetivar de maneira prática. Os pobres, que são a maioria da população brasileira, ficam 
totalmente dependentes das políticas sociais compensatórias para que a previsão constitucional tenha alguma possibilidade de efetivamente ser cumprida.

O inciso IV do art. 206 prevê a gratuidade do ensino público, o que implica em o ensino ser oferecido sem nenhum tipo de ônus, seja pecuniário ou não. Todavia, a prática dos estabelecimentos escolares da rede pública é a de estabelecer um pagamento através da "taxa de contribuição espontânea", cobrada através das APMs, ou solicitar "doações" aos alunos e comunidade para a aquisição de materiais ou pequenos bens para os estabelecimentos.

Segundo Victor Henrique Paro, inúmeros argumentos podem ser colocados contra ou a favor de tais cobranças ocorridas no contexto escolar.

Os vários argumentos a favor e contra a existência da APM com sua função arrecadadora de recursos da população colocam-se diante de um sério dilema. Por um lado, não há dúvida nenhuma que a população deve ter o direito à educação escolar de boa qualidade, sendo, portanto uma perversidade cobrar (por meio da APM) por um serviço pelo qual ela já pagou, quer por meio dos impostos, quer por meio da exploração inerente às relações capitalistas de produção. Por outro lado, depara-se com a realidade de uma quase totalidade de pais, alunos, professores e funcionários favoráveis à cobrança da taxa com a finalidade de remediar um pouco o descalabro da situação escolar. Esse impasse parece delinear uma situação limite para a qual não cabem soluções simplistas. (PARO, 1996. p. 137.

Na prática, a gratuidade do ensino público não é "tão gratuita" assim; o ônus existe, seja velado ou não, através de doações e contribuições espontâneas ou quaisquer outras denominações que sejam criadas para justificar sua necessidade, fruto da desobrigação do Estado com a educação pública.

Os dispositivos constitucionais em uma sociedade onde os indivíduos usufruem de igualdade real e não apenas formal deveriam ser impositivos e não facultativos. No entanto, esse não é o caso da sociedade brasileira, onde a divisão de classes e o distanciamento entre elas é determinante para as relações entre a efetividade concreta dos direitos do cidadão e a previsão legal. Embora os dispositivos constitucionais se efetivem na materialidade social conforme os interesses de classe, é preciso compreender que eles demonstram uma intencionalidade, dando indicativos para a efetivação do direito à educação na atualidade. No entanto, a sua efetivação depende, também, de instituições que garantam o cumprimento das exigências legais de forma igualitária. Não podemos desconsiderar que a criação e manutenção de tais instituições são de responsabilidade do poder público.

A Constituição deveria, em tese, ser conhecida de todos e efetivamente cumprida. A qualidade da educação brasileira está prevista e se traduz no conjunto de ações que necessitam ser colocadas em prática e não apenas constarem do texto escrito. Eis aqui algumas contradições existentes entre aquilo que se prevê e o que efetivamente é colocado em prática. Para tanto, os preceitos constitucionais devem se realizar na materialidade concreta, na própria realidade brasileira, possibilitando um avanço qualitativo nos processos educacionais.

Um Brasil uno em sua multiplicidade, moderno e efetivamente democrático será realidade quando oferecer ao seu povo reais condições de inclusão e cidadania. Isso possibilitará o rompimento com uma 
realidade perversa e dualista de um passado ainda presente. (CURY, 2002).

Embora a Constituição Brasileira possa estar eivada de contradições, se suas prescrições fossem vivenciadas concretamente pela totalidade da sociedade, poderia desenvolver possibilidades para a superação da realidade excludente, na qual a maioria da população se encontra.

Tanto a Constituição Federal de 1988, como a Lei de Diretrizes e Bases da Educação Nacional - Lei 9394/96 prevêem a obrigatoriedade e gratuidade da escola pública para o ensino fundamental. Embora esses dispositivos legais não sejam garantia de mudança na realidade existente, podem ser considerados como um avanço, ainda mais quando se cria a possibilidade de que o ensino fundamental tenha maior duração.

Em 2001 quando o Plano Nacional de Educação entrou em vigor, através da Lei 10.172, de 09 de janeiro daquele ano, houve a possibilidade de ampliação da duração do ensino fundamental. Aquele documento, ao fazer um diagnóstico do Ensino Fundamental no país e analisar a situação do inchaço de matrículas existentes no ensino fundamental causada pela distorção idade-série, apontou para a possibilidade da criação de um ensino fundamental com duração de nove anos, estabelecendo em seus objetivos e metas tal intenção.

Ampliar para nove anos a duração do ensino fundamental obrigatório com início aos seis anos de idade, à medida que for sendo universalizado $o$ atendimento na faixa de 7 a 14 anos. (BRASIL, 2001).

Nota-se uma preocupação com a necessidade de oportunizar mais tempo na escola para os alunos do ensino fundamental, ampliando-se a duração do mesmo. Todavia, Lisete Arelaro alerta para os interesses que possam estar implícitos nesta proposta:

É importante destacar as dificuldades que poderão advir dessa decisão política, pois dos 34,5 milhões de alunos matriculados no ensino fundamental regular do Brasil, somente 520 mil deles já vêm iniciando seus estudos aos 6 anos de idade. O que gera dois tipos de questões: a primeira, sobre a origem dessa proposta, defendida pelo governo anterior e expressa no Plano Nacional de Educação (PNE), plano este elaborado por esse mesmo governo e aprovado nas férias docentes de 2001 (Lei $\mathrm{n}$. 10.172, de 9/1/2001). Se o governo anterior não defendia e educação infantil, como responsabilidade do Estado, propondo inclusive que as parcerias com a comunidade fossem a forma de expansão desse atendimento, é possível que, assumindo um ano a "mais" no ensino fundamental, os outros anos dela - de 0 a 5 - eventualmente pudessem ser assumidos pelas comunidades. (ARELARO, 2005, p. 1046).

Essa preocupação mostra-se importante no contexto político educacional brasileiro visto que inúmeras propostas implementadas mostraram-se ineficazes em relação ao compromisso de assegurar o direito à educação de milhares de brasileiros.

$\mathrm{O}$ ingresso das crianças mais cedo no ensino obrigatório atende a uma política de eqüidade social, principalmente num país onde esse segmento da educação foi marcado historicamente pelo descompromisso governamental, que sempre atendeu aos interesses das classes dominantes. Contudo, essa opção precisa ser avaliada com cuidado para que a sua implementação não incorra em uma "inclusão excludente", segundo a qual um maior número de crianças estará dentro da escola, sem que esta esteja pedagógica, financeira e 
estruturalmente preparada para receber e atender tais alunos em suas necessidades educacionais.

O ensino fundamental, conforme previsto constitucionalmente, é obrigatório e gratuito, sendo dever do Estado a sua garantia. Portanto, ao ampliar o ensino fundamental para 9 anos, incluindo as crianças de 6 anos, o poder público não pode fazê-lo parcial ou facultativamente, mas, sim, oportunizando acesso de todos os alunos que se enquadrem nos requisitos, podendo, inclusive, ser responsabilizado pelo não oferecimento ou pela sua oferta irregular, conforme previsto no $\S 2^{\circ}$ do artigo 208 da Constituição Federal.

Com a sanção da Lei 11.274/06, em fevereiro de 2005, o ensino fundamental de 9 anos se tornou obrigatório no País, com matrícula dos alunos aos 6 anos de idade, alterando os artigos 32 e 87 da Lei 9394/96. O art. 32 passou a vigorar com a seguinte redação "O ensino fundamental obrigatório, com duração de 9 (nove) anos, gratuito na escola pública, iniciando-se aos 6 (seis) anos de idade, terá por objetivo a formação básica do cidadão,".

Assim, conforme previsto legalmente, os Municípios, e supletivamente o Estado e a União, deverão: matricular todos os educandos a partir dos 6 (seis) anos de idade no ensino fundamental (conforme previsto na alteração dada ao art. 87, $\S 3^{\circ}$, I da Lei 9394/06). Isso quer dizer que a obrigatoriedade para esse nível da educação básica ficou estabelecida para as crianças que completassem 6 anos de idade. Essa medida pode ser considerada como extremamente significativa em um país onde a maioria das crianças pequenas não frequienta qualquer instituição de educação formal, e, portanto, o acesso mais cedo à escola pode contribuir significativamente para a conquista da cidadania. Mas, é preciso ressaltar que apenas ampliar o tempo de duração da escolaridade obrigatória sem criar mecanismos que possibilitem a permanência e aprendizado dos alunos na escola é medida que permanece no campo da utopia.

Na perspectiva de contribuir para o usufruto da cidadania por todos os brasileiros, a ampliação da escolaridade obrigatória carrega consigo a responsabilidade em reorganizar a educação como um todo, visando ultrapassar o simples acesso à escola, ampliando as possibilidades de aquisição dos conhecimentos para toda a população. Quando isso não acontece a cidadania fica mutilada e como tal deixa de existir.

\section{CONCLUSÃO:}

A educação como direito social e como um dos componentes da consolidação da cidadania de um povo pressupõe a criação e efetivação de estratégias pelo poder público para que o mesmo seja garantido no âmbito da concretude. O movimento histórico de se fazer política e educação no país nos leva a concluir que o direito à educação obrigatória está localizado em espaços contraditórios, onde estão presentes os interesses sociais, econômicos e culturais. Defender o direito à educação nesses espaços é necessidade permanente enquanto perdurar a injustiça e a desigualdade entre seres humanos divididos em classes.

Para que a educação possa contribuir para a efetivação da cidadania do povo brasileiro é preciso entendê-la enquanto direito, ou seja, a garantia da educação deve ocorrer integralmente e não apenas como possibilidade de acesso à escola, pois para que esta contribua com o exercício da cidadania de forma geral, precisa ser organizada de forma a possibilitar que seus alunos usufruam de todas as possibilidades de acesso, aquisição e desenvolvimento de novos conhecimentos para o exercício de seus direitos e deveres. Para isso ocorrer é preciso efetivar ações que garantam a previsão legal. 


\section{REFERÊNCIAS:}

AZEVEDO, Fernando de. et. al. Manifesto dos pioneiros da Educação Nova (1932) e dos educadores (1959). Recife: Fundação Joaquim Nabuco/Editora Massangana, 2010.

ARELARO, Lisete Regina G. O ensino fundamental no Brasil: avanços, perplexidades e tendências. Educação e Sociedade. Campinas, vol. 26, n. 92, p. 1039 - 1066, Especial, out. 2005.

BENEVIDES, Maria Victoria. Ai que saudade do MDB. In: Revista Lua Nova. São Paulo: Brasiliense/CEDEC, vol. 3, n. 1, abr/jun,; 1986, p. 31.

BRASIL. Lei $n^{\circ}$ 4.024, de 20 de dezembro de 1961. Fixa as Diretrizes e Bases da Educação Nacional. Disponível em:

<http://www.planalto.gov.br/ccivil_03/Leis/L4024.htm\#art116>. Acesso em 02 fev. 2011.

BRASIL. Lei $n^{\circ}$ 5.692, de 11 de agosto de 1971. Fixa as Diretrizes e Bases do ensino de $1^{\circ}$ e $2^{\circ}$ graus e dá outras providências. Disponível em:

<http://www.planalto.gov.br/ccivil_03/Leis/L5692.htm>. Acesso em: 02 fev. 2011.

BRASIL, MEC. Plano Nacional de Educação. Brasília, 2001.

COSTA, Messias. A educação nas constituições do Brasil: dados e direções. Rio de Janeiro: DP\&A, 2002.

CUNHA, Luiz Antonio. Educação e classes sociais no Manifesto de 32: perguntas sem respostas. In: Revista da Faculdade de Educação da USP, vol 20, n. 1 e 2, p. 132 -150. jan. - dez., 1994.

CURY, Carlos Roberto Jamil. Legislação educacional brasileira. 2. ed. Rio de Janeiro: DP\&A ,2002.

FERNANDES, Florestan. Educação e Sociedade no Brasil. São Paulo: Dominus, 1966.

FREIRE, Paulo. Escola Primária para o Brasil. Revista Brasileira de Estudos

Pedagógicos. Brasília: INEP/MEC, vol. XXXV, n. 82, abr./jun. 1961. p. 15 - 33.

IANNI, Octávio. A sociedade global. 8 ed. Rio de Janeiro: Civilização Brasileira, 1999.

MANACORDA, Mario Alighero. História da Educação: da antiguidade aos nossos dias. 12 ed. São Paulo: Cortez, 2006.

NEVES, Lúcia M. W. Educação e política no Brasil de hoje. 2 ed. São Paulo: Cortez, 1999.

OLIVEIRA, Francisco de. O Estado no capitalismo monopolista. In: O serviço social nas relações sociais: movimentos populares e alternativas de políticas sociais. São Paulo: Cortez, 1987.

PARO, Victor Henrique. Administração Escolar: introdução crítica, $7^{a}$ ed. São Paulo: Cortez, 1996.

RIBEIRO, Maria Luisa Santos. História da educação brasileira: a organização escolar, $11^{a}$ ed., São Paulo: Cortez/ Autores Associados, 1991

ROMANELLI, Otaíza de Oliveira. História da Educação no Brasil (1930/1973), 8 a ed., Petrópolis: Vozes, 1986.

Revista HISTEDBR On-line, Campinas, n.43, p. 285-303, set2011 - ISSN: 1676-2584 302 
SAVIANI, Dermeval. História das idéias pedagógicas no Brasil. Campinas/SP: Autores Associados, 2007.

SHIROMA, Eneida. O.; MORAES, Maria Célia Marcondes de; EVANGELISTA, Olinda. Política educacional. Rio de Janeiro: DP\&A, 2000.

SPÓSITO, Marília Pontes. A luta pelo direito à educação: a década de 70. In: A

ilusão fecunda: a luta por educação nos movimentos populares. São Paulo: Hucitec: Edusp, 1993.

WARDE, Mirian. O Manifesto de 32: reconstrução educacional no Brasil. Revista ANDE,São Paulo, n.5, 1982

\section{Notas:}

${ }^{1}$ O texto apresentado faz parte dos estudos realizados ao longo do curso de doutorado ao PPGE da Universidade Federal de São Carlos - UFSCar a qual culminou com a defesa da tese intitulada "Direito à educação e ampliação da escolaridade obrigatória em Ponta Grossa - 2001 - 2008", e que teve como foco central de investigação a ampliação da escolaridade - Ensino Fundamental de 9 anos, enquanto medida político-educacional que tem como essência a ampliação do direito à educação através do acesso à escola e, conseqüentemente, a ampliação de condições reais para a melhoria da qualidade da escola brasileira.

${ }^{2}$ Doutora em Educação e Professora Adjunta da Universidade Estadual de Ponta Grossa (UEPG). E-mail: eflach@uol.com.br.

3 Segundo a Pesquisa Nacional de Amostra por Domicílio -2008, realizada pelo IBGE, o índice de analfabetos com mais de 10 anos no Brasil atinge o percentual de 9,8\% da totalidade da população. Considerando que a estimativa da população brasileira no ano de 2008 era de aproximadamente 193 milhões de pessoas é possível mensurar o número de analfabetos existentes no País.

Recebido em: $\quad 20 / 02 / 11$

Aprovado em: $\quad 04 / 04 / 11$ 